\title{
AVERSÃO AO RISCO E RESPOSTA COMPORTAMENTAL: UMA EXPLORAÇÃO HISTÓRICO-ECONÔMICA
}

Tácito Augusto Farias'; Paulo Henrique Salim²; Reinan Ribeiro Souza Santos ${ }^{3}$.

1 - Professor associado e Doutor em Economia e Finanças — Departamento de Economia UNIVERSIDADE FEDERAL DE SERGIPE-UFS. Líder do grupo de pesquisa em Economia Matemática e Finanças; credenciado no CNPQ/UFS. Membro/Tutor do grupo de pesquisa em Contabilidade e Finanças; credenciado no CNPQ/UFS. Doutor em Ciências — Economia Aplicada — UNIVERSIDADE DE SÃO PAULO-USP.

2 - Engenharia de Produção-UFS. Mestrado em Economia-UFS. Engenheiro de Produção da Petrobrás. 3 - Possui graduação na Escola Brasileira de Economia e Finanças pela Fundação Getúlio Vargas (2013), mestrado em Matemática pelo Instituto Nacional de Matemática Pura e Aplicada (2008) e doutorado em Economia pela Universidade Federal de Pernambuco (2020). Atualmente é professor adjunto da Universidade Federal da Bahia.

\section{Resumo}

O conceito de risco é hoje usualmente inserido na modelagem da economia financeira que consegue com sua ótica mais atual mensurá-lo de forma quantitativa, mas nem sempre esse foi o caso. Nesse artigo fazemos uma abordagem histórica de como o risco foi interpretado em diferentes épocas desde o início da sua compreensão qualitativa até a abordagem quantitativa atual, essa evolução contribui para a análise moderna da economia financeira e é incorporado na racionalidade dos agentes econômicos, mostramos ainda como essa incorporação ocorreu nos diferentes modelos econômicos e mais recentemente como revoluciona as finanças quantitativas com a mensuração dos ativos com risco. O comportamento individual mostra significante relação com a aversão ao risco mesmo assim podem existir situações em que o mesmo indivíduo pode estar propenso a assumir um maior risco, esse paradoxo mostra como o risco é uma teoria em evolução e importante para o debate atual.

Palavras-chave: Risco; Mensuração do risco; Economia financeira.

JEL: B30; G10. 


\title{
Risk aversion and behavioral response: A historical- Economic exploitation
}

\begin{abstract}
The concept of risk is usually inserted in the modeling of the financial economics, which, using its most current perspective, can measure it quantitatively, but this has not always been the case. In this article we take a historical approach to how risk was interpreted at different times from the qualitative beginner until the current quantitative approach, this evolution contributes to the modern analysis of the financial economy and is incorporated into the rationality of economic agents, we also show how this incorporation occurred in the different economic models and more recently as it revolutionizes quantitative finance with the theory of asset pricing. Individual behavior shows a significant relationship with risk aversion, even so, there may be situations in which the same individual may be prone to taking a greater risk, this paradox shows how risk is an evolving theory and important for the current debate.
\end{abstract}

Keywords: Risk; Measurement of risk; Financial Economics. 


\section{INTRODUÇÃO}

A concepção do risco constitui uma das ideias centrais que distinguem os tempos modernos dos mais remotos. Foi a batalha intelectual que traçou um recorte epistemológico preciso entre o que a humanidade entendia das orientações dos oráculos e adivinhos, passando a utilizar as ferramentas poderosas da análise e gerenciamento do risco disponíveis nos dias de hoje. Para Bernstein (1996), a história do risco é uma saga ricamente integrada de filósofos gregos e matemáticos árabes, de mercadores e cientistas, jogadores e filósofos, intelectuais de renome mundial e amadores obscuros, mas inspirados, que ajudaram a descobrir os métodos modernos de colocar o futuro a serviço do presente, substituindo a impotência diante do destino pela escolha e decisão. O risco afeta os aspectos mais profundos da psicologia, matemática, estatística, história e principalmente da economia.

Atualmente compreendemos bem a natureza aleatória do risco, imprevisível mesmo, de uma vasta gama de fenômenos. Mas ainda, assistimos a um espantoso florescimento do pensamento estocástico, que hoje domina e orienta setores tão diversos da atividade humana como o cálculo de prêmios de seguro e a determinação do preço de opções no mercado de bolsa, dentre outros (BERNSTEIN, 1996).

Objetivando realizar esta exploração histórica e econômica da aversão ao risco e a resposta comportamental, o artigo está cartesianamente decomposto buscando responder a quatro perguntas: (1). O que é risco? (2). Por que nos preocupamos com o risco? (3). O que se pensa sobre o risco?; (4). Como mensuramos o risco, sendo tais perguntas respondidas através da abordagem histórica, adicionando-se a teoria econômica.

A segunda seção inicia-se com o estudo do risco assinalando sua presença ao longo da história para depois analisar a formação de sua definição conceitual. A terceira seção comenta a atração exercida pelo risco e a maneira como ele afeta o comportamento através das principais teorias econômicas. Na quarta seção são examinadas evidências empíricas sobre a aversão ao risco, além de ser discutido se a visão comportamental deve substituir parcial ou complemente a visão econômica tradicional que se tem sobre o risco. 
A evolução dos agentes econômicos (sociedade, firmas e consumidores) é resultado da recompensa de algum risco assumido previamente e continuamente administrado. Conforme ressalta Bernstein (1996), a ideia revolucionária que define a fronteira entre os tempos modernos e pós-modernos com o passado é o domínio do risco: a noção de que o futuro é mais do que um capricho dos Deuses e de que homens e mulheres não são agentes econômicos passivos ante a natureza.

\section{O QUE É O RISCO}

O risco é parte de qualquer empreitada humana e elemento do avanço da civilização - da invenção de ferramentas pelo homem das cavernas até a terapia genética - foi possível porque algum agente econômico se dispôs a correr os riscos de desafiar o estado das coisas de então (DAMODARAN, 2008). Ao longo da maior parte da histórica da civilização, risco e sobrevivência andam paralelamente. O homem pré-histórico vivia uma vida breve e brutal, a procura por alimento e abrigo o expunha aos perigos da natureza. De fato, nos primórdios de nossa história, risco (dano físico) e retorno (recompensa material do alimento) sempre foram positivamente correlacionados. O homem das cavernas que corria riscos poderia conseguir ou não seu alimento. Já o homem que não corria o risco morria de fome, já tinha concretizada a perda da chance de obter alimentos. A máxima de que "não existe almoço de graça" do laureado economista Milton Friedman tem sua lógica na história do risco-retorno desde a pré-história.

Em 1000 a.C., os babilônios haviam desenvolvido um sistema em que os mercadores que faziam empréstimos para transportar seus carregamentos em barcos tinham a escolha de pagar um valor extra para anular o empréstimo caso a carga fosse roubada. Os gregos e os romanos apresentaram as primeiras apólices de seguro de vida com as sociedades beneficentes, que zelavam pelas famílias dos membros de suas sociedades quando estes morriam (DAMODARAN, 2008).

Para Bernstein (1996), a concepção moderna de risco tem suas raízes no sistema de numeração indoarábico que alcançou o Ocidente há cerca de setecentos a oitocentos anos. Mas o estudo formal do risco começou no Renascimento, quando as pessoas se libertaram das restrições do passado e desafiaram abertamente as crenças consagradas. Foi uma época que boa parte do mundo seria descoberto e seus recursos explorados. 
O advento das embarcações trouxe um novo campo para os aventureiros buscarem o risco. Os vikings construíram navios usando tecnologia para navegar da Escandinávia à Grã-Bretanha e Irlanda e até mesmo através do Atlântico, chegando às Américas em busca de novas terras para pilhar. Tal procedimento à época, era uma forma de risco (uso de recursos, conflitos armados e naufrágios) e de retorno (bens pilhados, abusos, dentre outros). O desenvolvimento da negação mercantil desenhou novas equações para risco e retorno, com o risco em Gênova e Veneza e daí para a Europa. Os espanhóis e holandeses, seguidos pelos ingleses, levaram esse comércio até as Índias Ocidentais por meio de uma rota marítima totalmente nova (BERNSTEIN, 1996).

Os comerciantes de Londres, Lisboa e Amsterdã, com o auxílio das monarquias dos respectivos países (uma espécie de Parceria-Público-Privada da época), investiam em navios e suprimentos necessários a suas longas viagens. Os perigos no caminho eram inúmeros, e a perda de metade ou até mesmo de toda a carga era fato comum; contudo, os polpudos preços das especiarias em seus destinos viabilizavam economicamente as empreitadas (uma precificação do risco nos preços para garantir um retorno). Se as empresas mercantilistas tivessem decidido proteger-se de todos os riscos, provavelmente não teriam os resultados alcançados nos séculos XIV e XV (DAMODARAN, 2008).

O mercado de especiarias não foi o único a viver essa epopeia. As atividades econômicas tal como praticadas até a revolução industrial muitas vezes traziam, àqueles que nelas se envolviam, riscos físicos com recompensas econômicas. Foram nesses cenários que os exploradores espanhóis zarparam para o Novo Mundo, cientes de que corriam risco real de vida - mas igualmente certos de que seriam recompensados com fartura, se obtivessem sucesso. Foi assim também que os jovens ingleses partiram para os postos avançados do Império Britânico na Índia e na China, com a esperança de fazer fortuna expondo-se a riscos de vida, de doenças e de guerra (BERNSTEIN, 1996).

Ao longo da história, muitas das duradouras e valiosas invenções emergiram tanto do desejo de eliminar o risco, quanto da exposição a ele. Considere mais uma vez o exemplo do comércio de especiarias. Os riscos inerentes às viagens marítimas e às forças hostis geraram uma necessidade de equipamentos melhor adaptados ao mar e de armas mais poderosas e rápidas. Os primeiros exemplos 
concretos de apólices de seguros e de combinação de riscos apareceram quase que simultaneamente. Existiram tentativas esporádicas anteriores de oferecer seguros, mas a primeira correta de seguros organizada foi fundada em 1688 por um grupo de mercadores, armadores e subscritores na Lloyd's Cooffe Shop em Londres, em respostas às demandas de proteção pelo risco a que estaria exposto o empreendimento. O surgimento da Lloyd's como a primeiro grande seguradora foi sustentado pelos avanços na avaliação de probabilidade e subsequente desenvolvimento de medidas estatísticas para o dimensionamento do risco (BERNSTEIN, 1996).

Ao longo das últimas décadas, os mercados financeiros viram o aparecimento de inovações a uma velocidade estonteante. Algumas destas inovações foram concebidas para auxiliar investidores e empresas a protegerem-se contra riscos, mas muitas vezes vêm sendo apresentadas como meios para explorar riscos em busca de retornos extraordinários. Em alguns casos, as mesmas ferramentas financeiras (opções, futuros, swaps, dentre outros) desempenham papel tanto de hedge quanto de exploração de riscos, a ainda que para diferentes públicos (HOLTON, 2004).

Já as definições de risco variam dentro de um amplo espectro. Algumas definições se concentram principalmente na probabilidade de ocorrência de eventos negativos; outras consideram as consequências desses eventos, enquanto há aquelas que consideram tanto o lado e perdas quanto o de ganho de distribuição de eventos. A dualidade risco-retorno está no cerne da moderna definição do risco (DAMODARAN, 2008). Em 1921, Frank Knight resumiu a diferença entre risco e incerteza:

“...A Incerteza precisa ser considerada como um sentido radicalmente distinto da noção comumente aceita de Risco, da qual nunca foi adequadamente separada... O aspecto essencial está no fato de "Risco" significar, em alguns casos, uma variável passível de ser medida, enquanto em outros o termo não aceita esse atributo; além disso, há enormes e cruciais diferenças nas consequências desses fenômenos, dependendo de qual dos dois esteja realmente presente e operante... Está claro que uma incerteza mensurável ou o risco propriamente dito, na acepção que utilizaremos, é tão diferente de uma incerteza não-mensurável, que não se trata, de forma alguma, de uma incerteza.”. 
Em suma, Knight (1921) definiu apenas a incerteza quantificável como sendo risco. A ênfase no aspecto subjetivo ou objetivo da incerteza foi criticada por quase todos economistas em análises posteriores. Para Holton (2004), há dois ingredientes para o risco se configurar. O primeiro é a incerteza sobre os prováveis resultados de um experimento, e o segundo é o fato de que os resultados obtidos precisam ser relevantes em termos de utilidade. Como exemplo, o ideograma chinês da Figura 1 para o termo "risco" é uma combinação do termo "perigo" (crise) e "oportunidade", e representa tanto o lado dos riscos de perda (downside risk) quanto o lado dos riscos com oportunidades (upside risk), numa distribuição de resultados. Esta é a definição mais moderna.

Figura 1 - ideograma chinês de risco.

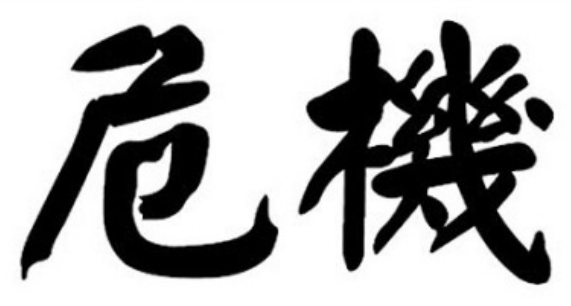

Danger Opportunity

Fonte: desenvolvido pelos autores.

\section{O PORQUÊ DA PREOCUPAÇÃO COM O RISCO}

Para Damodaran (2008), em um mundo em que as pessoas praticam esportes radicais e os jogos de azar são um negócio de bilhões de dólares, está claro que os seres humanos, coletivamente, sentem-se por vezes atraídos pelo risco, e que alguns são mais suscetíveis a essa atração do que outros. Para Bernstein (1996), enquanto os psicanalistas do início do século XX consideravam o risco como uma doença, o fato desse comportamento ser tão difundido na humanidade sugere que o fascínio pelo fenômeno é parte da natureza humana, ainda que nenhuma recompensa racional a essa exposição seja escolhida. Contudo, também há evidências de que o ser humano tenta evitar risco em suas empreitadas pessoais. 
Ao passo que a história demostra evidências de riscos e da maneira como os seres humanos reagiram diante dele, a Teoria Econômica recorre a funções de utilidade para definir a relação ao menor risco econômico. Para a economia neoclássica, os agentes econômicos fazem escolhas com objetivo de maximizar a utilidade esperada e não a riqueza.

O primeiro trabalho nesta linha foi elaborado por Bernoulli (1738). Em primeiro lugar, ele observou que o valor atrelado a uma aposta específica (descritas em "O Paradoxo de São Petersburgo") varia de acordo com as preferências individuais. Ou seja, alguns indivíduos estão dispostos a pagar mais do que outros, sendo essa diferença uma função da aversão ao risco. Em segundo lugar, a utilidade em ganhar um dólar adicional diminui com a riqueza. Assim, o ganho de um montante é muito mais importante para um pobre do que para um rico. Bernoulli (1738) trouxe o argumento que a utilidade marginal da riqueza diminui à medida que esta aumenta, uma opção que se insere na essência da maioria das teorias econômicas tracionais. Por mais simplista que possa parecer, o experimento de Bernoulli foi a bandeirada de largada para a análise científica dos riscos.

Ao mesmo tempo que o argumento para utilidade marginal decrescente pareça bastante razoável, é possível que a utilidade aumente a uma taxa muito semelhante à do aumento da riqueza para alguns investidores, ou mesmo a uma taxa maior do que a taxa de aumento da riqueza. Com essas possibilidades, temos o agente avesso ao risco, indiferente ao risco e amante do risco. Na figura 2 é possível verificar o comportamento dos três perfis frente aos riscos.

Figura 2 - Utilidade e riqueza
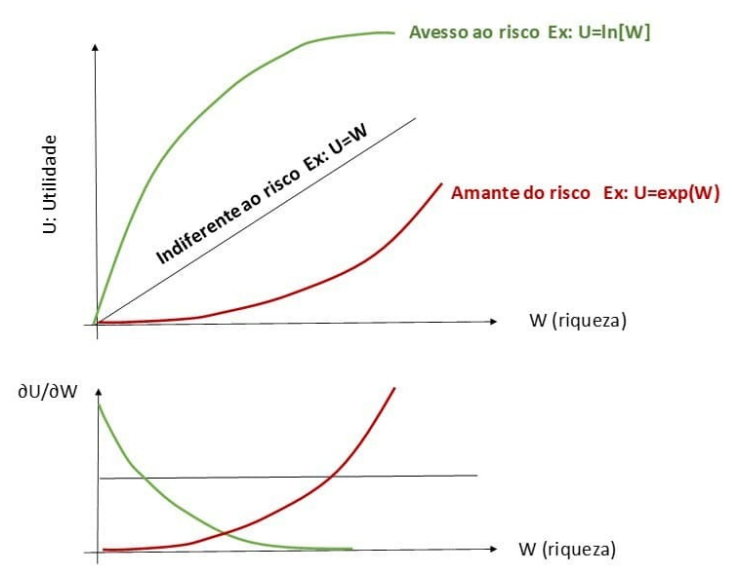

Fonte: elaborado pelo autor. 
Pela proposta de Bernoulli (1738), o importante é a utilidade e não a riqueza em si, de onde se deduz que a aversão ao risco pode variar muito entre as pessoas. Para Pratt (1964), os coeficientes de aversão ao risco representam extensões naturais das funções utilidade. Especificando a relação entre a utilidade e riqueza por meio de uma função, o coeficiente de aversão ao risco mede a utilidade obtida (ou perdida) à medida que aumentamos (ou diminuirmos) nossa riqueza. Dado o seguinte coeficiente de aversão ao risco:

$$
\text { Aversão ao risco de Arrow-Pratt (absoluto) }=-\frac{\frac{\partial^{2} U}{\partial W^{2}}}{\frac{\partial U^{2}}{\partial W}}
$$

O índice, quanto positivo, mede a aversão absoluta ao risco, e aumenta com o grau de aversão ao risco. Matematicamente, um agente econômico avesso ao risco possui utilidade marginal decrescente, ou seja: $\frac{\partial U}{\partial W}>0$ e $\frac{\partial^{2} U}{\partial W}<0$. Abaixo, temos a versão relativa para o mesmo indicador.

$$
\text { Aversão ao risco de Arrow-Pratt (relativo) }=-W \frac{\frac{\partial^{2} U}{\partial W^{2}}}{\frac{\partial U}{\partial W}}
$$

A vantagem dessa fórmula está na possibilidade de comparar resultados entre agentes econômicos com diferentes funções de utilidade e assim tirar conclusões. Contudo, Ross (1981) argumenta que os axiomas de aversão ao risco de Arrow-Pratt podem gerar resultados contra intuitivos, quando os agentes precisam escolher entre duas alternativas de risco.

Nas apostas apresentadas por Bernoulli (1738), e outros, sucesso e fracasso tinham a mesma probabilidade de ocorrer, apesar da variação nos resultados. Enquanto Bernoulli (1738) teve a percepção crítica de vincular utilidade à riqueza, Von Neumann e Morgenstern (1953) focaram a discussão sobre a utilidade da esfera dos resultados para a probabilidade. Eles argumentaram que a utilidade esperada por indivíduos diante de um jogo pode ser especificada em termos tanto dos resultados quanto das probabilidades de esses resultados ocorrerem, e que esses indivíduos escolhem uma dada modalidade de aposta com base na maximização da utilidade esperada. 
Os argumentos de Neumann e Morgenstern (1953) para utilidade são baseados no que eles chamaram de axiomas básicos da escolha. O primeiro desses axiomas, intitulado comparabilidade (ou completude), exige que as diferentes apostas ou escolhas sejam comparáveis e que os indivíduos sejam capazes de especificar suas preferências para cada uma delas. O segundo, transitividade, exige que se uma pessoa prefere a aposta $\mathrm{A}$ à aposta $\mathrm{B}$ e a $\mathrm{B}$ à $\mathrm{C}$, consequentemente prefere $\mathrm{A}$ à $\mathrm{C}$. $\mathrm{O}$ axioma de independência especifica que os resultados de cada evento são independentes entre si. Conforme Damodaran (2008), é o mais importante e polêmico dos axiomas da escolha. Em síntese, estamos supondo que a preferência entre duas loterias não é afetada se elas forem combinadas da mesma maneira com uma terceira loteria.

O quarto axioma básico da escolha, a mensurabilidade, exige que a probabilidade de diferentes resultados em cada aposta seja mensurável. Finalmente, o axioma da classificação pressupõe que se um indivíduo classifica os resultados $\mathrm{B}$ e $\mathrm{C}$ entre $\mathrm{A}$ e $\mathrm{D}$, as probabilidades de gerar apostas às quais ele seja indiferente (entre $\mathrm{B}$ e $\mathrm{A}+\mathrm{D}$, e $\mathrm{C}$ e $\mathrm{A}+\mathrm{D})$ têm de ser consistentes com as classificações feitas. Esses axiomas permitiram a Neumann e Morgerstern (1953) derivar funções de utilidade esperadas conforme a Equação (3), em que E (U|Pi) representa o valor esperado da utilidade para um dado evento Pi.

$$
E(U)=\sum_{i=1}^{n} E\left(U \mid P_{i}\right) \times P_{i}
$$

Friedman e Savage (1948) argumentaram que as pessoas podem, ao mesmo tempo, ser avessas ao risco e ter preferência pelo risco para diferentes segmentos de riqueza. Eles postularam que os agentes econômicos são capazes de adotar comportamentos irracionais quando defrontados por escolhas arriscadas em certas circunstâncias.

Em um famoso estudo Paul Samuelson (1963) analisou duas oportunidades de aposta. Na primeira, ao jogar a moeda o jogador ganharia $\$ 200$, se desse cara, e perderia $\$ 100$, se desse coroa, em uma única jogada. Na segunda oportunidade, valeriam as mesmas regras, mas seriam possíveis 100 chances. O resultado foi uma nítida preferência pela segunda opção. Samuelson (1963) argumentou que a recusa em participar da primeira oferta e a aceitação em participar da segunda era inconsistente com a teoria da 
utilidade esperada, e que o erro provavelmente ocorreu porque houve erros de interpretação da variância de uma série de apostas como sendo menor do que a variância de um único lançamento.

Nas últimas décadas, houveram algumas tentativas de pesquisadores, insatisfeitos com a teoria convencional da utilidade, ou desconcertados com a dimensão do apoio empírico a ela dado, de descobrir caminhos alternativos para explicar a aversão ao risco (DAMODARAN, 2008). O ponto de partida para muitos dos questionamentos acerca da teoria da utilidade esperada de NeumannMorgenstern foi o paradoxo exposto por Maurice Allais (1979) em dois pares de escolhas de apostas, apresentadas no Quadro 1.

Quadro 1 - Apostas possíveis

$$
\begin{array}{ll}
P_{1} & \$ 100 \text { com } 100 \% \text { de chance } \\
P_{2} \quad \begin{array}{l}
\$ 0 \text { com } 1 \% ; \$ 100 \text { com } 89 \% \text { e } \$ 500 \\
\text { com } 10 \% \text { de chances. }
\end{array}
\end{array}
$$

Pela utilidade teríamos $\quad U\left(P_{1}\right)=100 \times 1=100 \quad$ e $U\left(P_{2}\right)=[0 \times 0,01+100 \times 0,89+500 \times 0,1]=139$. A maioria dos indivíduos preferiu a opção $P_{1}$ , contrariando a lógica racional de $P_{2} \succeq P_{1}$ (pois $U\left(P_{2}\right)>U\left(P_{1}\right)$ ), mas consistente com aversão ao risco do indivíduo, pois a aposta $P_{1}$ possui variância igual a zero, diferentemente da aposta $P_{2}$. Na segunda análise, Allais (1979) ofereceu a esses mesmos indivíduos duas outras apostas:

Quadro 2 - Apostas possíveis, segunda rodada

\begin{tabular}{|ll|}
\hline$Q_{1}$ & $\begin{array}{l}\text { \$ } 0 \text { com } 89 \% \text { e } \$ 100 \text { com } 11 \% \text { de } \\
\text { chances; }\end{array}$ \\
\hdashline$Q_{2}$ & $\begin{array}{l}\text { \$ } 0 \text { com } 90 \% \text { e } \$ 500 \text { com } 10 \% \text { de } \\
\text { chances. }\end{array}$ \\
\hline
\end{tabular}


Logicamente $Q_{2} \succeq Q_{1}$, pois $E\left(Q_{2}\right)>E\left(Q_{1}\right)$. Assim, Allais (1979) observou que a maioria dos indivíduos mudava de opinião preferindo $Q_{2}$ a $Q_{1}$. De forma ao explicar esse paradoxo, Allais discordou do cálculo de utilidade esperada de Neumann e Morgestern, argumentando que a utilidade esperada em uma aposta deveria refletir não apena a utilidade dos resultados e as probabilidades dos resultados ocorrerem, como também as diferenças de utilidades obtidas com esses resultados. Assim, a preferência por $Q_{2}$ é explicada meramente pelo fato de a variância entre as utilidades ser muito alta. Havendo defeitos no axioma de independência, a partir da qual a teoria da utilidade se constrói.

Machina (1982) propôs que o axioma da independência fosse abandonado e que a dominância estocástica fosse empregada para obter funções que ele chamou de utilidade esperada local. Em termos intuitivos, ele supôs que as pessoas se tornavam mais avessas ao risco à medida que as possibilidades melhoravam, o que influenciaria a maneira com que escolhemos entre loterias arriscadas.

Loomes e Sugden (1982) relaxaram o axioma da transitividade da teoria convencional da utilidade esperada para desenvolver o que chamaram de teoria do arrependimento. No centro desta teoria está a premissa de que os indivíduos comparam os resultados obtidos em uma loteria, e desapontam-se quando esses resultados divergem de forma não favorável daquilo que eles poderiam ter ganho. Assim, diferenças grandes entre o que se ganha e o que se poderia ter ganho dão margem a arrependimentos desproporcionalmente elevados. O resultado final é a possibilidade de se observarem ações inconsistentes com a teoria convencional da utilidade esperada. Segundo Damodaran (2008), o problema de modelos como os de Allais, Lomes, Sugden e Machina é que eles nem sempre são internamente consistentes, e ao mesmo tempo em que explicam alguns dos paradoxos e anomalias existentes nos axiomas, geram novos paradoxos que não conseguem explicar.

Ao mesmo tempo que muitos economistas permaneceram dentro dos limites convencionais da racionalidade e tentaram aprimorar modelos que correspondessem de modo mais eficientes a realidade, Kahneman e Tversky (1979) substituíram a função de utilidade, que define a utilidade com função da riqueza $(U=U(W))$, por uma função valor, com o valor definido como os desvio de um ponto de referência que permite diferentes funções para perdas e ganhos, conforme Figura 3. 
Figura 3 - Função de aversão a perdas de Kahneman e Tversky

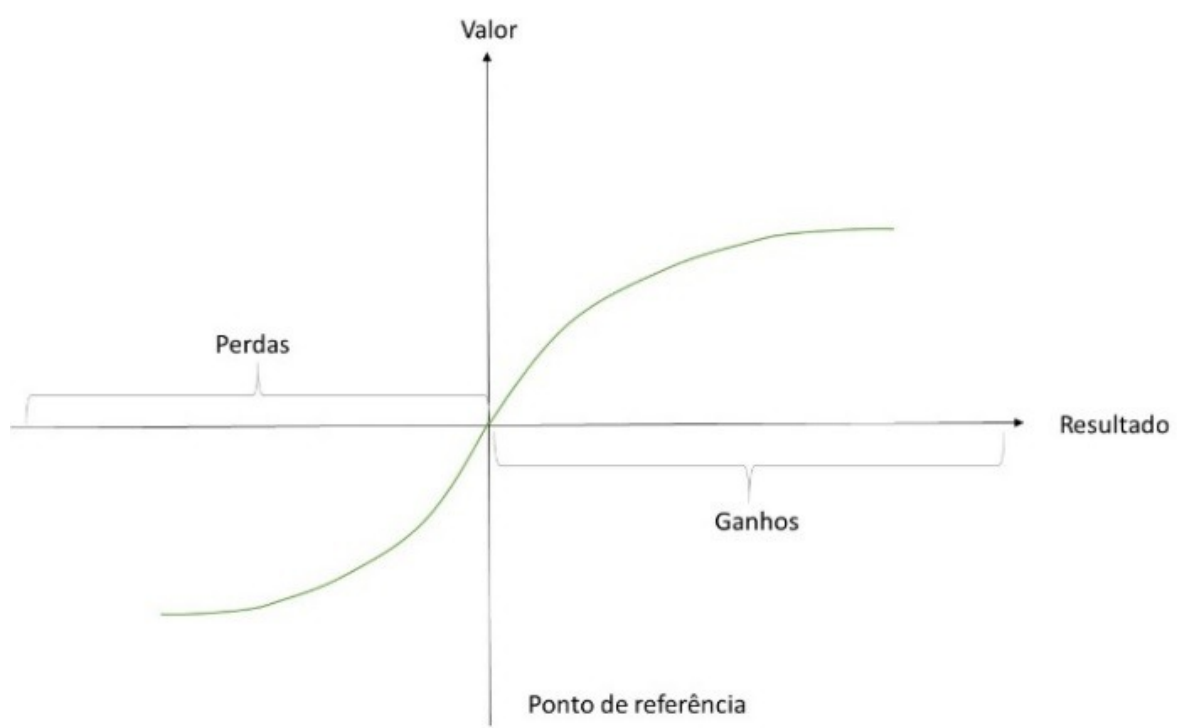

Fonte: Adaptado pelo autor com base em Kahneman e Tversky.

A implicação é que a maneira como as pessoas se comportam depende da maneira com que um problema é apresentado. A decisão será diferente se o resultado for apresentado para parecer um ganho em relação a um dado ponto de referência, ou uma perda em relação a um ponto de referência diferente. Colocando em termos de coeficientes de aversão ao risco comportam-se de modos diferentes (KAHNEMAN; TVERSKY, 1979).

Kahneman e Tversky (1979) também explicaram o paradoxo de Allais (1979) no que chamaram de efeito da consequência comum. $\mathrm{O}$ argumento apresentado pelos pesquisadores foi $\mathrm{o}$ de que as preferências podem ser influenciadas pelo que denominam de efeito do preço de consolo. Nele, a possibilidade de um resultado de grande efeito pode tornar os indivíduos muito mais avessos ao risco. Assim temos, uma nova representação para o paradoxo de Allais no Quadro 3.

Quadro 3 - Resultado de Allais sob a perspectiva de Kahneman e Tversky.

$$
\begin{gathered}
E\left(u ; P_{1}\right)=0,1 u(100)+0,89 u(100)+0,01 u(100) \\
E\left(u ; P_{2}\right)=0,1 u(500)+0,89 u(100)+0,01 u(0) \\
E\left(u ; Q_{1}\right)=0,1 u(100)+0,01 u(100)+0,89 u(0) \\
U\left(u ; Q_{2}\right)=0,1 u(500)+0,01 u(0)+0,89 u(0)
\end{gathered}
$$


Observa-se que o preço comum entre o primeiro par de escolhas (P1 e P2) é 0,89u(100), o que é muito maior do que o prêmio existente em comum entre o segundo par de escolhas (Q1 e Q2) que é de 0,89u(0). Com maior prêmio em comum do primeiro par, o indivíduo fica mais avesso ao risco do que diante do segundo par com prêmio muito menor. O trabalho de Kahneman e Tversky (1979) foi revolucionário, pois sugeriu que o problema com a teoria da utilidade esperada não estava em um outro axioma, mas na visão do comportamento humano adotado pelos axiomas.

\section{O PENSAMENTO SOBRE O RISCO}

A maior parte da teoria econômica construiu-se sobre a tese da racionalidade dos agentes econômicos e da aversão ao risco. Nesse contexto, a noção de utilidade marginal decrescente, introduzida por Bernoulli (1738), permanece no cerne da discussão econômica. Mas conforme Kahneman e Tversky (1979), existem anomalias sistemáticas no comportamento humano incompatíveis com o exercício da razão.

As descobertas de Bernoulli (1738), de que a maioria das pessoas está disposta a pagar quantias relativamente pequenas para participar de uma loteria com valor esperado infinito, deram início à teoria da utilidade esperada e lançaram as bases para a maneira como medimos a aversão ao risco na Teoria Econômica. Em busca de apoio à teoria, os experimentos de Allais na década de 1950 mencionados na seção anterior, acabaram trazendo evidências de que a teoria tradicional da utilidade esperada não era sustenta por testes práticos, e de que os seres humanos se comportam de modo muito mais complexo do que modelos matemáticos tentavam explicar.

Nas décadas posteriores, vários estudos de laboratório sobre aversão ao risco foram conduzidos, alguns dos quais utilizaram animais. Um desses estudos, o de Batallio, Kagel e MacDonald (1985), usou como modelo animal ratos que tiveram que escolher entre uma alternativa segura (uma fonte constante) e uma alternativa com risco (uma fonte variável de alimento). A conclusão foi de que os ratos eram avessos a riscos em suas escolhas, e apresentavam uma aversão em leve queda à medida que seu consumo de alimento aumenta. Cavigelli (2003), em uma deprimente conclusão sobre seres humanos 
avessos ao risco, concluiu que ratos mais avessos ao risco viviam menos e sob maior estresse do que aqueles que expressavam menor aversão.

Outros estudos com seres humanos concluíram que somos realmente avesso ao risco, embora com diferenças de aversão, dependendo de quanto está em jogo e de como o um experimento é estruturado. Um desses estudos propôs a seus participantes, que tinham diferentes níveis de riqueza, escolherem entre investimentos garantidos e investimentos com risco. Os resultados indicaram aversão absoluta decrescente entre os participantes. Porém, esses resultados não revelaram qualquer evidência de aversão relativa crescente - a proporção de riqueza que estavam dispostos a arriscar não diminui com o aumento da riqueza (LEVY, 1994).

Em suma, parece haver uma clara evidência de que os seres humanos, em geral, são avessos ao risco e de que esse sentimento aumenta quanto maior a quantia em jogo. Também há evidências de diferenças significativas em aversão ao risco entre indivíduos, pois alguns não demonstram qualquer sinal de aversão, enquanto outros mesmo buscam o risco (DAMODARAN, 2008).

No Quadro 4 é possível verificar diferentes situações experimentadas para diversas outras situações.

Quadro 4 - Economia experimental envolvendo o comportamento sobre o risco

Situação

Loteria versus leilões

Configuração institucional

\section{Conclusões da pesquisa}

Berg e Reitz (1998) descobriram que indivíduos poucos avessos aos riscos, ou mesmo indiferentes aos riscos, nas escolhas de loterias tornavam-se muito mais avessos em jogos envolvendo barganhas e em leilões interativos.

Berg, Dickhaut e McCabe (2005) compararam a maneira como um mesmo grupo de pessoas formula preço para ativos (e dessa forma revela suas preferências pelo risco) em um leilão aberto de segundo preço e em um leilão de preço fechado. Os autores descobriram que o comportamento dos participantes se descola da preferência de risco no leilão aberto de segundo preço para a aversão ao risco no leilão de preço fechado.
Efeito da informação

Homem

versus mulher
Kahneman, Schwartz, Thaler e Tversky (1997) descobriram que as pessoas que recebiam feedback com mais frequência eram mais avessos ao risco.
Diferenças raciais e culturais
Byrnes, Elron e Cohen (1999) descobriram que as mulheres além de serem definitivamente mais avessas ao risco, são menos propensas a assumir investimentos com risco. 
As evidências sobre a aversão ao risco originam-se de uma variedade de fatos, e existem tantos resultados semelhante quanto diferenças em cada abordagem. Contudo, Damodaran (2008) afirma que há evidências e consensos acerca do assunto:

- As pessoas em geral são avessas ao risco, e essa aversão aumenta com o quanto que está em jogo. Apesar das diferenças entre os estudos, as evidências apoiam a visão de que as pessoas estão dispostas a investir grandes quantias em ativos com risco (aversão absoluta decrescente ao risco) à medida que enriquecem. Contudo, as evidências são confusas quanto à aversão relativa, que apoiam tanto a aversão relativa crescente quanto a decrescente ou a constante em diferentes configurações experimentais;

- Há grandes diferenças em termos de aversão ao risco entre diferentes populações, e diferenças observáveis entre subgrupos de uma mesma população. As mulheres tendem a ser mais avessas ao risco do que os homens, e as pessoas idosas mais do que as jovens;

- As pessoas são muito mais afetadas pelas perdas do que pelos ganhos equivalentes (aversão à perda), e esse comportamento acirra-se com monitoramento constante (miopia);

- As escolhas que as pessoas fazem (e a aversão ao risco que manifestam), quando diante de escolhas com risco ou loterias, dependem de como a escolha é apresentada (do quadro de preferências);

- As pessoas tendem a ser mais predispostas a assumir riscos com o que consideram "dinheiro achado no chão" do que com valores que tiveram que trabalhar para ganhar (o efeito do dinheiro da casa);

- Há dois cenários em que a aversão ao risco parece diminuir e até mesmo ser substituída pela preferência pelo risco. O primeiro corre quando as pessoas possuem a oportunidade de ganhar uma grande quantia com uma pequena possibilidade de sucesso (viés do azarão). O outro cenário ocorre quando as pessoas que perderam dinheiro têm diante de si escolhas que permitem reaver as quantias que perdem (efeito da busca do equilíbrio entre perdas e ganhos, comum em jogos como poker);

- Quando se deparam com escolha com risco, seja em experimentos ou em shows de auditório, as pessoas muitas vezes cometem erros ao avaliarem as probabilidades dos resultados possíveis, superestimando as chances de sucesso. Esse problema agrava-se com o aumento da complexidade das escolhas (por exemplo, o Show do Milhão que ocorria na TV brasileira e que voltou a ser produzido nas televisões do mundo todo. 
Em suma, é difícil aceitar a noção de um único agente econômico com função de utilidade e coeficiente de aversão ao risco representativo para uma população heterogênea, dadas as diversidades em aversão e as anomalias entre as pessoas (pelo menos da perspectiva de alguém perfeitamente racional em busca de utilidade), tão difíceis de estruturar cientificamente.

Para Bernstein (1996), a transformação nas atitudes em relação à administração do risco desencadeada por suas realizações canalizou a paixão humana pelos jogos e apostas para o crescimento econômico, a melhoria da qualidade e o progresso tecnológico.

\section{A MENSURAÇÃO DO RISCO}

Diante da responsabilidade imputada ao destino e à Divina Providência que caracterizou a maneira como o risco foi considerado até a Idade Média, é interessante o fato que tenha sido um monge italiano, Lucas Pacioli, professor de Leonardo DaVinci, o primeiro a discutir sobre a mensuração do risco, ao apresentar em 1794, um problema que confundiu muitas pessoas por quase dois séculos. A solução para o quebra-cabeça, e os seus desdobramentos posteriores, lançaram as bases para as modernas medidas de risco. O problema consistia em dois jogadores em um jogo de dados no qual vence aquele que obtém o melhor resultado em cinco. No jogo, um dos participantes está na frente, por dois arremessos a um. A questão é saber qual a medida justa de dividir o prêmio entre eles, na situação em que o jogo é impedido de continuar e considerando o resultado parcial da interrupção (BERNSTEIN, 1996).

O primeiro passo para resolver o quebra cabeça de Pacioli foi dado no início do século XVI por um médico e jogador, Giraldo Cardano, que estimou as probabilidades dos diferentes resultados de um jogo de dados. Suas observações foram reunidas em um livro intitulado Livros sobre Jogos de Azar, em que Cardano, estima não somente a probabilidade de um número específico sair no lançamento de dado (1/6), como também avalia as chances de obter valores em dois lançamentos consecutivos; ele, por exemplo, estimou a probabilidade de ocorrer dois resultados " 1 " consecutivos como sendo de 1/36 (DOMINGUES, 1933). 
Somente em 1654 o problema de Pacioli ganhou solução completa, quando Pascal e Fermat consideraram todos os resultados possíveis (espaço amostral) para o problema e afirmaram que, com dados não viciados, o jogador que estivesse na frente por dois jogos contra um, na série de melhor de cinco, teria três chances de vencer em quatro, e assim deveria levar $75 \%$ do prêmio. Nesse cálculo, os matemáticos definiram as bases para probabilidades e sua utilidade em não apenas explicar o passado.

Décadas depois, Bernoulli (1711) enuncia a "lei dos grandes números", provando que uma amostragem aleatória de itens de uma população tem as mesmas características, na média, da mesma população vista como um todo. A generalização de populações por meio de amostragens é uma prática que permeia as ciências econômicas e sociais até hoje. Em 1738, Moivre apresenta a distribuição normal como uma aproximação às distribuições binominais à medida que se aumenta o tamanho amostral. Já a curva em forma de sino, que caracteriza a distribuição normal, foi refinada por outros matemáticos, aí se incluíam Laplace e Gauss (DAMODARAN, 2006).

Uma das vantagens da distribuição normal é que ela pode ser descrita com apenas a média e o desvio padrão, variáveis fundamentais na avaliação dos riscos. Mas foi Bayes (1763) que publicou uma maneira simples de atualizar as crenças existentes à luz de novas evidências. Na estatística bayesiana, as crenças existentes são chamadas de probabilidade "a priori", ou incondicionais, e os valores revisados depois de considerar novas evidências são chamados de probabilidades "a posteriori” ou condicionais. Assim, Bayes (1763) criou uma importante ferramenta para os pesquisadores que precisavam usar probabilidade a fim de avaliar a chance de resultados negativos ocorrerem e atualizar essas probabilidades à medida que esses eventos transcorriam, inovação fundamental para a emergente indústria de seguros.

Segundo Damoradaran (2009), em 1875 Francis Galton descobriu a regressão à média, que explica por que o orgulho precede a queda, e por que as nuvens tendem a ter superfícies prateadas. Pela teoria, sempre que os agentes tomam uma decisão baseados na expectativa de que as coisas voltarão ao normal (padrão), existe a noção de regressão à média.

Com o desenvolvimento do mercado de ações e de títulos de renda fixa em todo o mundo no século XIX, os investidores passaram procurar por medidas de risco mais concretas. Uma vez que investidores 
em ativos colhem os resultados tanto positivos quanto negativos de suas empreitadas, a noção de risco como sendo função sobretudo de perdas deu lugar a ideia de que o risco poderia ser fonte de ganhos (DAMODARAN, 2008).

Segundo Bernstein (1996), o acesso às informações era restrito, e a maneiras de processá-las eram escassas no século XVIII e XIX. Não é surpresa que as medidas de risco eram qualitativas e de sentido amplo. Os investidores dos mercados financeiros daquela época definiam risco em termos de estabilidade da renda gerada por seus investimentos no longo prazo e pela conservação do capital. Na hierarquia de riscos da época, as obrigações de longo prazo dos governos ocupavam o lugar das mais seguras, seguidas pelos títulos de dividas emitidos pelas firmas e pelas ações que pagavam dividendos. Séculos depois, a hierarquia continua semelhante.

Considerando que não havia medidas quantitativas de risco para ativos financeiros, os investidores tratavam grupos inteiros de investimentos como se compartilhassem o mesmo nível de risco (KNIGHT, 1929). Assim, as ações eram classificadas como arriscadas e impróprias para investidores avessos ao risco, independentemente do rendimento dos dividendos que geravam. Uma forma alternativa era a classificação dos investimentos com base nas informações disponíveis sobre a entidade emitente. Segundo Damodaran (2006), ações emitidas por uma empresa bem-sucedida e com sólida reputação eram consideradas mais seguras do que as ações emitidas por qualquer entidade desconhecida. Em resposta a esse comportamento impreciso dos investidores, as companhias passaram a oferecer mais dados sobre suas operações e disponibilizá-las aos potenciais investidores.

Já no início do século XX, haviam serviços de coleta de dados sobre os retornos e preços de títulos individuais, que computavam estatísticas básicas como retorno esperado e desvio padrão dos retornos. Por exemplo, em 1909, a Financial Review of Reviews publicada no Reino Unido, examinou carteiras de dez títulos, incluindo obrigações, ações preferenciais e ações ordinárias, medindo a volatilidade de cada título utilizando preços ao longo de dez anos. Na verdade, essa publicação trouxe o argumento a favor da diversificação, ao estimar o impacto da correção em suas carteiras (DAMODARAN, 2006). 
Em 1909, Louis Bachelier, considerado o fundador da moderna teoria de finanças, examinou o comportamento dos preços e opções ao longo do tempo. Em sua tese de doutorado, Théorie de la Spéculation, Bachelier (1909) introduziu o conceito de movimento Browniano dando início ao uso dos conceitos de finanças em tempo contínuo.

O modelo proposto para a dinâmica dos preços foi o processo aritmético browniano, por esta razão o modelo foi criticado em virtude da possibilidade de ocorrência de preços com valores negativos. Mesmo com este fato, o estudo do modelo é justificável, não só por razões históricas, mas também pelo uso na avaliação de opções sobre a margem ou diferença entre dois ativos (spread options). O modelo de Bachelier (1909) pressupõe que a dinâmica dos preços dos ativos Xt é um processo aritmético Browniano, ou seja,

$$
d X_{t}=\mu d t+\sigma d B_{t}
$$

$\mathrm{Na}$ forma integral temos:

$$
X_{t}=z=\mu t+\sigma B_{t}
$$

Bachelier (1909) verificou que havia pouca correlação entre a variação nos preços em dado período e variação nos preços no período seguinte, lançando as bases para a hipótese do caminho aleatório dos preços (random walk) e dos mercados eficientes, apesar de essas ideias terem aparecido quase 60 anos depois.

Quase simultaneamente, o acesso e a confiabilidade dos relatórios financeiros emitidos por firmas estavam melhorando, e os analistas passavam a conceber medidas do risco baseadas nos números contábeis. Índices de rentabilidade (como margem sobre capital próprio) e de alavancagem financeiras (dívidas sobre o capital próprio) passaram a ser usados como representações do risco do negócio. Este tipo de análise de risco, existente até hoje, desconsidera os preços das ações e foca nos fundamentos econômicos e financeiros da firma. Entre 1909 e 1915, a Standard Statistics Bureau, a Moody's e a Fitch passam a classificar títulos de dívidas de empresas por meio de informações contábeis (BERNSTEIN, 1996). 
As técnicas de avaliação econômica de projetos que usam fluxo de caixa descontado (FCD) derivam de modelos originalmente desenvolvidos para o ambiente de certeza foram desenvolvidas por Fisher (1985), e posteriormente (décadas de 1950 e 1960) adaptadas para o ambiente de incerteza. Contudo, Fischer (1930) reconhecia a importância das opções nos investimentos:

"Eu prefiro o termo oportunidade de investimento... O conceito de oportunidade de investimento apoia-se sobre o da opção. Uma opção é qualquer fluxo de renda possível, aberta a um indivíduo pela utilização do seus recursos, capital, trabalho, terra, dinheiro, para produzir ou assegurar esse fluxo de renda. Uma oportunidade de investimento é a oportunidade de mudar de opção, ou flixo de renda opcional, para outra".

(Capítulo 7, The Theory of Interest The Theory of Interest as Determined by Impatiente to Spend Income and Opportunity to Invest It).

Abaixo temos na Equação (6) o fluxo de caixa descontado para tempo discreto e na Equação (7) para o tempo contínuo.

$$
\begin{gathered}
F C D=\sum_{t=0}^{n} \frac{\text { Fluxo de caixa t }}{(1+\text { taxa })^{t}} \\
F C D=\int_{t=0}^{n} \operatorname{Fluxo}(t) \times e^{-\operatorname{taxa} x t} d t
\end{gathered}
$$

Segundo Dias (2013), no início, a taxa de fluxo de caixa representava apenas o valor do dinheiro no tempo, sendo depois incorporado um ajuste ao risco nessas taxas. $\mathrm{Na}$ época, inegavelmente, representaram uma evolução às teorias que se fundamentavam em modelos de equilíbrio de mercado, sendo que a mais notável teoria dessa época foi o Capital Asset Princig Model.

Graham (1949) advogou contra medidas de risco baseadas em preços passados (volatilidade), e observou que quedas nos preços podem ser temporárias, sem refletir o verdadeiro valor da companhia baseado nos seus fundamentos operacionais, econômicos e financeiros. 
Segundo Damodaran (2006), na década de 40 Van Neumann e Ulam (1946) fizeram um trabalho de simulação numérica para solucionar problemas de blindagem em reatores nucleares. Este trabalho foi a origem do método de Monte Carlo, que consiste em uma técnica de amostragem artificial empregada para operar numericamente sistemas complexos que tenham componentes aleatórios. Esse método foi chamado de Monte Carlo, pois utiliza um processo aleatório, tal como lançamento de dados ou o girar de uma rola para poder selecionar dados da variável de entrada do modelo.

A utilização da Simulação de Monte Carlo na decisão de investimento está associada sobre tudo a David Hertz (1964), com seu clássico artigo Risk Analysis in Capital Investment. Essa metodologia, incorporada a modelos de finanças fornece aproximações para as distribuições de probabilidade dos parâmetros que estão sendo estudados. Embora careça de uma forte teoria econômica, o método de Monte Carlo é amplamente utilizado na prática econômica empresarial.

Por volta de 1950, os investidores dos mercados financeiros empregavam medidas de risco baseadas em preços passados e informações contábeis em conjunto com categorias de risco amplo, baseadas no tipo de título e na reputação do emitente, para fazerem seus julgamentos sobre risco. Contudo, não havia um consenso sobre a melhor maneira de mensurar riscos e a exata relação entre o risco e retorno esperado (BERNSTEIN, 1996).

O grande marco teórico do gerenciamento de diversos ativos (portfólio) e revolução das finanças quantitativas ocorreu com Harry Markowitz (1952) em seu artigo "Portfolio Selection", onde é estruturada matematicamente a relação entre dois fatores para o investidor: risco e retornos esperados. Influenciado pelos estudos sobre incerteza de Neumann, Friedman, Savage e Willian, este físico verificou que as decisões de seleção de ativos não deveriam estar baseadas apenas nos retornos esperados, mas também nos riscos envolvidos tanto individualmente quanto em conjunto, baseado nas correlações entre os ativos (DAMODARAN, 1996). Tais riscos são associados à volatilidade dos valores das ações, representadas muitas vezes por medidas tais quais seu desvio padrão.

Segundo Damodaran (2008), a crença de que a diversificação era benéfica aos investidores já existia bem antes de Markowitz. A revista britânica Financial Review of Reviews de 1909 usou correlações 
entre títulos para defender o argumento de que os investidores deveriam dividir suas apostas e que uma carteira diversificada ofereceria menos riscos do que o investimento em um único título, sem implicar em retornos diferentes. Contundo, Markowitz alterou a maneira como pensamos sobre riscos ao se vincular a variabilidade presente de uma carteira de investimentos aos co movimentos entre os ativos individuais naquela carteira.

Uma das maiores contribuições dos estudos de Markowitz (1952 e 1959) foi ressaltar a importância da diversificação, conceito contestado por importantes acadêmicos. O conceito da diversificação deriva da observação que os preços dos ativos financeiros não se movem de modo exatamente conjunto, i.e., eles possuem uma correlação imperfeita. Nesta condição, a variância total de uma carteira será reduzida pelo fato que a variação no preço individual de um ativo é compensada por variações complementares nos preços dos demais. Tais constatações podem ser verificadas matematicamente pela Equação (8) da variância total da carteira, onde $\sigma_{i}$ representa o desvio padrão do ativo i, $x_{i}$ a participação do ativo i na carteira e $\rho_{i j}$ a correlação entre os dois ativos.

$$
\operatorname{var}(\text { portifólio })=\sigma p^{2}=\sum_{i=1}^{n} \sigma_{i}^{2} x_{i}^{2}+\sum_{i=1}^{n} \sum_{i=1}^{n} \rho_{i j} \sigma_{i} \sigma_{j} x_{i} x_{j}
$$

Um dos conceitos mais importantes que derivam da Teoria do Portfólio é a Fronteira Eficiente (MARKOWIT, 1952). Na figura 4 pode-se observar que uma carteira como a formada pelo ponto A não seria conveniente, pois a carteira $\mathrm{B}$ - para o mesmo retorno - tem menor risco, e a carteira $\mathrm{C}$ - para o mesmo risco - tem maior retorno.

Figura 4 - Fronteira Eficiente.

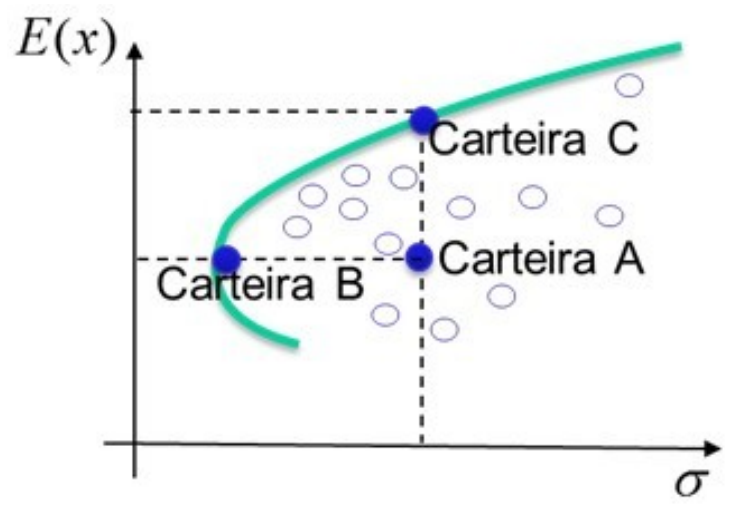


A curva que contém as melhores combinações em termos de risco e retorno, ou seja, os portfólios de maior retorno para um dado nível de risco, é chamada de Fronteira Eficiente. De acordo com Markowitz (1970), se um portfólio é eficiente, é impossível obter um retorno maior sem incorrer em maior desvio padrão (e, portanto, risco), assim como é impossível obter menor desvio padrão sem diminuir o retorno médio. Depois de eliminados todos os "portfólios dominados", como aquele representado pela Carteira A na Figura 3, tem-se o portfólio eficiente.

A Figura 4 mostra o delineamento da fronteira eficiente quando há dois ativos. $\mathrm{O}$ eixo das ordenadas representa o retorno médio esperado (média ponderada entre o retorno do ativo e sua participação na carteira), enquanto o eixo das abscissas é a variância das carteiras. Cada curva representa a fronteira eficiente para um valor diferente de covariância entre as carteiras a e b. É interessante verificar que quanto menor o grau de correlação, mais encurvada é a fronteira eficiente, i.e., o efeito diversificação torna-se mais intenso quanto menor o coeficiente de correlação $\rho$. A curvatura mais acentuada ocorre quando $\rho=-1$, i.e., quando há correlação negativa perfeita entre os dois ativos.

Por simetria, a curvatura menos acentuada é quando $\rho=1$. Os casos extremos $(1 \mathrm{e}-1)$ são de pouca importância prática, uma vez que no mundo real a maioria dos ativos possui correlação positiva entre si.

Figura 5 - Análise de portfólio com dois ativos.

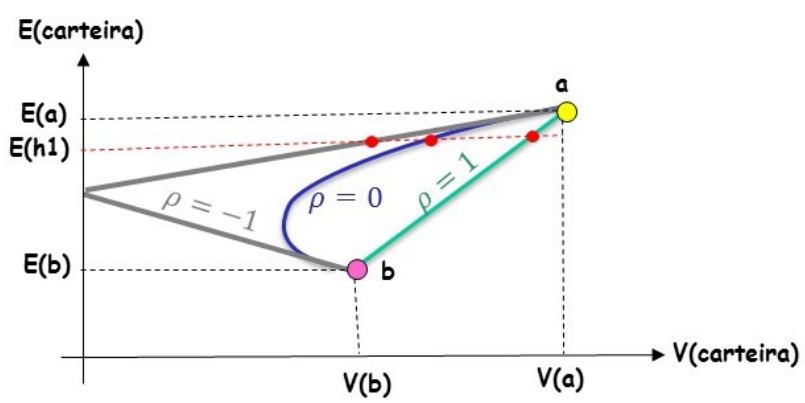

Fonte: Elaborado pelo autor.

Um modelo de programação não-linear pode ser formulado para o problema de determinação de um portfólio. Toda modelagem começa com a definição do problema real, no caso: a maximização do retorno esperado de uma carteira, constituída de ativos dentre uma quantidade $\mathrm{n}$ de possíveis opções, de 
forma a não ultrapassar um valor de risco pré-determinado. O risco é associado às variações nos valores dos ativos pertencentes à esta carteira.

Supondo um mercado de capitais com n ações passíveis de inclusão na carteira, o gestor de investimento tem como variáveis de decisão as cotas alocadas em cada ativo $x_{i}(i=1,2,3, \ldots, n)$. Estipulando que $\mu_{i}$ e $\sigma_{i}$ sejam, respectivamente, o retorno esperado e o risco (desvio padrão dos valores) de um determinado ativo i, estes dados tornam-se parâmetros para o modelo. Adota-se a premissa que estes valores podem ser mensurados por uma análise adequada. Outro parâmetro de grande importância no modelo é a covariância entre os ativos $\mathrm{i}$ e $\mathrm{j}$, representado neste modelo como $\sigma_{i j}$, para $j=1,2,3, \ldots, n(j \neq i)$ (HILLIER e LIEBERMAN, 2006). Um modelo do portfólio é estruturado tendo como função objetivo a maximização do lucro, que é o resultado dos valores esperados dos ativos. Assim, para um conjunto ativos selecionados $\left(x_{1}, x_{2}, \ldots, x_{n}\right)$ teremos uma variância, que para este problema é tida como uma restrição.

$$
\operatorname{Maximizar} R(x)=L=\sum_{i=1}^{n} \mu_{i} x_{i}
$$

Sujeito à

$$
\begin{gathered}
\sum_{i=1}^{n} \sigma_{i}^{2} x_{i}^{2}+\sum_{i=1}^{n} \sum_{i=1}^{n} \rho_{i j} \sigma_{i} \sigma_{j} x_{i} x_{j} \leq V(x) \\
\sum_{i=1}^{n} P_{i} x_{i} \leq B
\end{gathered}
$$

No modelo acima, temos a essência da maximização dos resultados financeiros $\mathrm{R}(\mathrm{x})$ sujeitos às restrições de orçamento $\mathrm{B}$ e de exposição ao risco $\mathrm{V}(\mathrm{x})$. Trata-se de uma decisão de balancear o portfólio, pois a decisão também estará atrelada ao preço do ativo, possibilitando ao gestor se desfazer de ações caras e comprar ações mais baratas.

A revolução iniciada por Markowitz foi levada à sua conclusão lógica por John Lintner (1965), Jack Treynor (1961) e Bill Sharpe (1961), com o desenvolvimento de seu modelo de precificação CAPM Capital Asset Princing Model. Sharp e Lintner acrescentaram um ativo sem risco a esse mix e concluíram que havia alternativa melhor para investidores a cada nível de risco, gerada pela alocação do 
ativo sem risco em uma carteira amplamente diversificada, situada na fronteira eficiente. As combinações de um ativo sem risco e de uma carteira eficiente geraram maiores retornos esperados para cada nível de risco em comparação com uma carteira única de vários ativos com risco.

Para investidores que desejam risco menor do que aquele inerente à carteira de mercado, essa abordagem se traduz em investir uma parcela de sua riqueza na carteira eficiente e o restante em ativos sem risco. Por outro lado, presume-se que os investidores que querem correr mais riscos fazem empréstimos à taxa sem risco e investem esse dinheiro em carteiras eficientes. Se todos os investidores seguem esse preceito, eles seriam investidores da carteira eficiente, que tem como característica a diversificação. É a chamada carteira de mercado. A equação (12) apresenta uma aplicação do CAPM para calcular o custo de capital de um determinado ativo.

$$
K e=K f+\beta \times(R m-K f)
$$

$\mathrm{Na}$ Equação (10), temos Kf a taxa livro de risco (SELIC para investimentos no Brasil); $\beta$ é o indicador de risco não diversificável do ativo, que pode ser substituído por $\frac{\operatorname{cov}(K e, R m)}{\operatorname{Var}(R m)}$ e Rm é a taxa de retorno esperada pela carteira de mercado, sendo no Brasil utilizava-se o índice ibovespa (IBOV:SP). Para empresas de capital fechado ou sem dados corretos, a análise deve ser realizada para empresas do mesmo setor e do mesmo porte.

Portanto, o CAPM estende o insight de Markowitz de que os investidores devem diversificar, para o seu limite lógico, em que detêm a carteira de mercado, com todos os ativos comercializados. Assim, o risco de qualquer ativo é a função da maneira como este ativo covaria com a carteira de mercado. Aceitar o CAPM exige a aceitação também dos pressupostos que o modelo faz sobre a informação e os custos de transação, além dos pressupostos subjacentes da estrutura da média-variância. Apesar de seus inúmeros críticos, a aceitação geral do modelo e sua sobrevivência como padrão para mensuração do risco até hoje são testemunhos da sua simplicidade e apelo intuitivo (DAMODARAN, 2008).

Desde o seu aparecimento a estrutura da média-variância é vítima de controvérsia. Segundo Damodaran (2008) há três grupos de contestação. O primeiro grupo defende que os preços das ações (em particular), e os retorno sobre os investimentos (em geral), apresentam um número excessivo de valores 
elevados, para ajustarem-se a uma curva normal. Esses argumentam que as "caudas gordas" das distribuições de preços de ações servem melhor a uma classe de distribuições chamada de distribuições da lei da potência, que exige variância infinita e longos períodos de dependência de preços. O segundo grupo discorda da simetria da distribuição normal e defende medidas que incorporem às medidas de risco a assimetria encontra nas destruições de retorno observados. O terceiro defende que as distribuições que permitem saltos de preços são mais realistas, e que as medidas do risco devem considera a probabilidade e a magnitude deste salto.

O primeiro desafio direto ao modelo CAPM surgiu em meados da década de 1970, quando Steve Ross (1976) desenvolveu o modelo de precificação por arbitragem (Arbitrage Princing Theory). Ele valeu-se da preposição fundamental de que dois ativos de mesma exposição ao risco têm de ter preços iguais, definidos pelo mercado, para evitar que os investidores gerem lucros sem risco (lucros de arbitragem). $\mathrm{O}$ autor defende que em um mercado em que não existam oportunidades de arbitragem, é possível obter medidas do risco com base nos retornos observados nos mercados. A técnica estatística empregada por Ross para obter essas medidas do risco foi a análise fatorial. O retorno de um ativo, Equação (13), dependeria de alterações inesperadas de fatores (Fi) e da sensibilidade do investimento a alterações inesperadas de $F_{i}\left(B_{i}\right)$, com a incidência de um erro aletório $(\varepsilon)$.

$$
R_{i}=K f+\sum_{i=1}^{n} B_{i} F_{i}+\varepsilon
$$

Enquanto os modelos de precificação por arbitragem restringem-se aos dados históricos de preços, os modelos multifatoriais incluem outros tipos de dados, como dados macroeconômicos em algumas de suas versões, e dados específicos a uma empresa (como índice de capitalização e preços) entre outras. Em síntese, os modelos multifatoriais partem da hipótese de que os preços do mercado em geral sobem e descem por alguma razão, e que as ações que geram altos retornos em períodos longos precisam ter maior risco do que aquelas que geram retorno menores nos mesmo intervalos (DAMODARAN, 2008). Estabelecidos esses pressupostos, esses modelos procuram por dados externos que possam explicas as diferenças nos retornos entre ações. Fama e French (1992), examinando a relação entre retorno sobre ações e fatores específicos a uma empresa, concluíram que a capitalização de mercado e o índice valor 
patrimonial/preço representam melhor o risco do que beta (CAPM) ou os betas (APT), conforme demonstrado na equação (14), sendo MV o valor de mercado das ações emitidas pela firma e BV o patrimônio líquido.

$$
\operatorname{Retorno}_{j}(\%)=1,77 \%-0,11 \ln \left(M V_{j}\right)+0,35 \ln \left(\frac{B V_{j}}{M V_{j}}\right)
$$

Em outras palavras, pesquisadores e gestores têm a escolha de procurar entre centenas de proxies em potencial e adotar os que funcionam melhor, uma prática comum na econometria.

Em 1954, Savage e Samuelson redescobrem a dissertação de Bachelier, e no final dos anos 1950 e início dos anos 1960 são publicados vários artigos discutindo modelos estocásticos de comportamento dos preços das ações, assim como tentativas de precificação de opções. Finalmente, na década de 1970, Black e Scholes (1973) e Merton (1973) estabeleceram as bases da moderna teoria das opções financeiras, ao desenvolverem um modelo que não precisa fazer nenhuma premissa restritiva sobre as preferências individuais em relação ao risco ou sobre a formação dos preços de mercado em equilíbrio.

\section{CONCLUSÃO}

A capacidade de definir o que poderá acontecer no futuro e de optar entre várias alternativas é central às sociedades contemporâneas. Analisar, avaliar e gerenciar riscos, junto à vontade de correr riscos e de fazer opções ousadas, são elementos-chave da energia que impulsiona os agentes econômicos.

Este artigo examinou a evolução das medidas de risco ao longo do tempo. Na maior parte da história, o homem atribuiu acontecimentos negativos ao destino ou à Divina Providência. Assim, foram poucos os esforços para mensurar o risco na esfera quantitativa. Afinal, se os deuses decidissem puni-lo, não haveria modo de mensurar o risco ou de geri-lo que salvariam desse castigo. A primeira ruptura nessa visão do risco ocorreu na Idade Média, quando os matemáticos apresentaram as primeiras medidas de probabilidades. Os avanços que se sucederam no campo da Estatística, entre outros - estenderam o alcance das probabilidades às incertezas que pessoas e empresas enfrentam diariamente. Com isso 
nasceu a indústria de seguros, em que companhias seguradoras oferecem proteção a pessoas e empresas contra possíveis perdas, e cobram um prêmio por essa salvaguarda.

O crescimento dos mercados de ativos financeiros gerou a necessidade de medidas do risco que capturassem tanto o risco de perda inerente a esses investimentos quanto o potencial para ganhos e lucros. O crescimento do setor de serviços que ofereciam estimativas para essas medidas do risco se dá em paralelo ao aumento no acesso à formação dos preços e aos dados financeiros sobre investimentos. Markowitz lançou as bases para a moderna teoria das carteiras ao tornar explícitas as vantagens da diversificação. Em sequência ao seu raciocínio sobre as carteiras eficientes, foram desenvolvidos vários modelos quantitativos para precificação do risco. Esses avanços históricos e metodológicos seguiram no fortalecimento das finanças quantitativas que passaram a dominar o todo o mercado financeiro internacional, possibilitando seu crescimento acelerado. Até hoje as finanças quantitativas vêm evoluindo em termos de metodologias chegando a equações bastantes complexas, dificultando a até mesmo o seu controle.

\section{Referências}

ALLAIS, M. "The So-Called Allais Paradox and Rational Decisions Under Uncertaintly" Allais and Hagen: Expected Utility Hypotheses and the Allais Paradox. Dordrecht: D. Reidel, 1979.

BACHELIER L. . Theorie de la speculation. Annales de l'Ecole Normale Superieure XVII, 3:21-86, 1900.

BATALLIO,R.C.;KAGEL,J.H.;MACDONALD,D.N. Animals Choices Over Uncertain Outcomes: Some Initial Experimental Results. The American Economic Review, vol 75, nº 4, 1985.

BAYES,R.T. An Essays Toward Solving a Problem in the Doctrine of Chances. Philos. Trans. R. Soc. London 53, 370-418, 1763. Reimpresso em Biometrika, 45, 293-315, 1958.

BERG,J.;REITZ,T. Do Unto Others: A Theory and Experimental Test of Interpersonal Factors in Decision Making Under Uncertainty. University Iowa, Discussion Paper, August,1997.

BERG,J.E.;DICKHAUT,J.;MCCABE,K. Risk Preference Instability across Institutions: A Dilema. PNAS, Vol. 102, 4309-4214, 2005. 
BERNOULLI, D. Exposition of a New Theory on the Mensurement of Risk, 1738. Disponível em: https://engineering.purdue.edu/ ipollak/ece302/FALL09/notes/Bernoulli_1738.pdf. Acessado em: nov/2016.

BERNSTEIN,P. Against the Gods: The Remarkable Story of Risk. NewYork/Canada: Ed. John Wiley e Sons, INC, 1996.

BLACK,F. The pricing of commodity contracts. Journal of Financial Economics, vol. 3, 167-179, 1976.

BLACK,F.;SCHOLES,M. The Pricing of Options and Corporate Liabilites. Journal of Political Economy, No 81, pp. 637-659, 1973.

CAVIGELLI,S.A.;MCCLINTOCK,M.K. Fear of novelty in infart rats predicts adult corticosterone dynamics and an early death. Anais da National Academy of the Sciences, 2003.

DAMODARAN, A. Gestão Estratégica de Riscos: uma referência para tomada de riscos empresariais. São Paulo: Ed. Bookman, 2009.

DIAS,M.A G. Analise de Investimentos com Opções Reais vol.1: teoria e pratica com aplicações em petróleo e em outros setores. Rio de Janeiro: Ed.Intercedência, 2013.

DOMINGUES,H. Cardano: o intelectual jogador. In: HAZZAN, Samuel. Fundamentos de matemática elementar. São Paulo: Ed. Atual, 1993.

FAMA,E.;MILLER,M.H. The Theory of Finance. New York: Holt, Rinehart \& Winston, 1972.

FRIEDMAN,M.;SAVAGE,L.P. “The Utility Analysis of Choice Involving Risk”. Journal of Political Economy, Vol. 56, 279-304, 1948.

GRAHAM, B. The Intelligent Investor. New York: McGraw Hill, 1949.

HERTZ, D. B. Risk Analysis in Capital Investment. Havard Business Review, pp. 95-106, 1964.

HILLIER, Frederick S., LIEBERMAN, Gerald J. Introdução à pesquisa operacional. São Paulo: McGraw-Hill, 2006.

HOLT,C.A.;LAURY,S.K.; Risk Aversion and Incentive Effects. The American Economic Review, Vol. $92, \mathrm{n}^{\mathrm{o}} 5,1664-1655,2002$.

HOLTON,G.A. Definig Risk. Financial Analysts Journal, 60(6), 19-25, 2006. 
KAHNEMAN,D.;SCHWARTZ,A.; HALER, R; TVERSKY, A. The Effect of Myopic Loss Aversion on Risk Taking: An Experimental Teste. Quarterly Journal of Economics. Vol 112., 647-661, 1997.

KAHNEMAN,D.;TVERSKY,A. Prospect Theory: Na Analysis of Decision Under Risk. Econometrica, Vol 47, 262-292, 1979.

KNIGHT,F.H. Risk, Uncertainty and Profit. New York: Hart, Schaffner, and Marx, 1921.

LEVY, H. Absolute and Relative Risck Aversion: An Experimental Study. Journal of Risk and Uncertainty, 8:3 (May), 290-307, 1994.

LOOMES,G.;SUDGEN,R. Regret Theory: Na Alternative of Rational Choice Under Uncertainty. Eco 92, 805-824, 1982.

MACHINA,M.J. Expected Utility Theory Without the Independence Axiome. Econometrica, 50, 277 $323,1982$.

MAKOWITZ, H. Portfolio Selection. The Journal of Finance, 1952.

MAKOWITZ,H. Portfolio Selection. The Journal of Finance, Vol 7, nº 1, 77-91, 1952.

MARKOWITZ,H. Portfolio Selection: Efficient Diversification of Investments. New York: Wiley, 1959.

MOIVRE,A.D. Doctrine of Chances. New York: Chelsea Publishing, 1978.

PRATT,I.W. Risk Aversion in the Small and in the Large. Econometrica, vol. 32, 122-136, 1964.

ROSS,S.A. Some Stronger Mensures of Risk Aversion in the Small and in the Large with Applications. Econometria, Vol. 49 (3), 621-639, 1981.

ROSS,S.A. The Arbitrage Theory of Capital Asset Princing. Journal of Economic Theory, Vol. 13(3), 341-360, 1976.

SAMUELSON,P. Risk and Uncerainty: A Fallacy of Large Numbers. Scientia, 98, 108-113, 1963.

SHARPE, W. F. Capital Asset Prices: A Theory of Markets Equilibrium under Conditions of Risk. Journal of Finance, 19(3), 425-442, 1961.

SHARPE,W.F. Capital Asset Prices: A Theory of Markets Equilibrium under Conditions of Risk. Journal of Finance, 19(3), 425-442, 1961. 
TREYNOR,J. The Valuation of Risk Assets and the Selection of Risky Investments in Stock Portfolios and Capital Budgets. The Review of Economics and Statistics, 47: 13-37, 1961.

VON NEUMANN,J.;MORGENSTERN,O. Theory of Games and Economic Behavior. 1953 Priceton: Ed. Priceton, NJ: Priceton University Press. 